\title{
A FIGURAÇÃO DO EXÍLIO NO CICLO FRANCÊS DE MILAN KUNDERA
}

\author{
Lorena do Rosário Silva ${ }^{1}$ \\ Anna Palma ${ }^{2}$
}

\begin{abstract}
Resumo: O objetivo desse estudo é evidenciar a figuração do exílio presente em três dos romances franceses do escritor tcheco-francês Milan Kundera: A lentidão (1995), A identidade (1997) e A ignorância (2000). Esse entendimento parte da contraposição das obras do ciclo tcheco com as do ciclo francês, além do entendimento das transformações decorrentes nelas. Logo, serão observadas as relações entre narrativa e exílio, sendo esse percebido como um agente que pode aparecer em forma de representações diretas e indiretas, durante essa nova fase de escrita nas narrativas em francês. Com isso, transita-se pelos romances acima citados e o livro de ensaios do romancista; bem como pelos textos que enfocam exílio, memória e identidade, entre outros. Por consequência, demonstra-se uma relação existente entre as imagens de memória evocadas (duração, espelhamento e repetição) e a experiência do deslocamento como produto de uma vivência em exílio.
\end{abstract}

Palavras-chave: Milan Kundera; Memória; Exílio.

Abstract: The aim of this study is to highlight the figuration of exile present in three of the French novels by the Czech-French writer Milan Kundera: Slowness (1995), Identity (1997) and Ignorance (2000). This understanding starts from the contrast of the works of the Czech cycle with those of the French cycle, in addition to the understanding of the transformations resulting from them. Next, the relations between narrative and exile will be observed, which is perceived as an agent that can appear in the form of direct and indirect representations, during this new phase of writing in French narratives. Thereby, moves up the novels mentioned above and the book of essays novelist; as well as for texts that focus on exile, memory and identity, among others. Consequently, a relationship exists between the evoked memory images (duration, mirroring and repetition) and the experience of displacement as a product of an exile experience.

Keywords: Milan Kundera; Memory; Exile.

1 Doutoranda em Estudos Literários pela Universidade Federal de Minas Gerais (UFMG).

2 Professora da Faculdade de Letras da UFMG. 


\section{INTRODUÇÃO}

Deslocamento. Movimento. Migração. Exílio. Tais termos fazem parte de muitas das narrativas contemporâneas do século XX. Afirmar isso não restringe o tema a esse momento histórico, muito pelo contrário, os registros literários que se debruçam sobre exílio são datados desde a antiguidade clássica: a Odisseia de Homero é o exemplo mais antigo de que se tem nota e narra as aventuras de Ulisses para retornar a Itaca e, consequentemente, a sua esposa, Penélope. Contudo, o domínio do termo não se limitou apenas à trama das narrativas, já que muitos escritores vivenciaram essa condição, se não foi, para os mesmos, o motivo principal que os levou à escrita literária.

O advento do século XX, com as constantes transformações na sociedade - a saber, a crescente onda de nacionalização e a defesa da soberania dos países - resultantes da substituição da dupla Estado-nação para a dupla Estado-sociedade3, contou também com grandes contribuições no que tange às reflexões sobre história e memória, de modo que o mundo passou a ser habitado e tensionado por esses dois campos. Em decorrência disso, surgiram inúmeras narrativas que se debruçam sobre as memórias, visando reconstituir um passado que é constantemente silenciado pelo peso da História. Tais textos vêm de encontro a uma necessidade de se oferecer outras perspectivas acerca de um momento ou período vivenciado por uma determinada sociedade, e muitos deles possuem temas em comum: autoritarismo, resistência e exílio.

Milan Kundera, como um autor em exílio, apresenta tais temas, ainda que nem sempre de forma explícita, nos seus romances e ensaios ${ }^{4}$ - oferecendo, ao mesmo tempo em que reflete sobre questões existenciais, uma diferente visão a respeito de acontecimentos históricos, seja de seu país de origem, República Tcheca5, seja do mundo. Dito isto, uma pequena biobibliografia merece ser trazida à luz antes do artigo prosseguir, até mesmo para que se possa, de fato, considerar as figurações do exílio presentes em suas narrativas do ciclo francês.

3 Conforme afirma Pierre Nora em seu artigo "Entre memória e história: a problemática dos lugares" (1993), a percepção da cisão entre história e memória se instaura a partir do modo como a constituição dos países se organiza, saindo da concepção Estado vinculada a uma nação (tentativa de independência e construção de um nome comum e construção da identidade nacional), para a de um Estado vinculado a uma sociedade (ideia onde a identidade já existe e encontra maneiras de se manter a permanência). No primeiro, a história e a memória estavam entrelaçadas no momento de constituição de uma história nacional comum; enquanto que no segundo, com a consolidação da identidade, história, memória e nação se tornam termos autônomos e, por isso, se separam dentro de seus conceitos - sendo a história transformada em ciência social e a memória em prática privada.

4 Com isso, pondero acerca do entendimento de que Milan Kundera opta por deixar que as suas obras reflitam sobre a existência e que, em algum momento, elas perpassam o autoritarismo, a resistência e o exílio; tendo em vista a sua compreensão de si como um romancista - alguém que desfaz a construção de sua vida e usa dos tijolos par criar algo - e a não limitação e redução de sua escrita (forma) a sua vivência (conteúdo).

5 Refiro-me à República Tcheca como forma de relacionar a um espaço geográfico localizado, porém é necessário afirmar que nisso há uma redução, por motivos práticos, do entendimento de uma localização que é perpassada por diversas transformações sociais e históricas e que pode ser vista igualmente como Tchecoslováquia ou Boêmia (que é o nome por muitas vezes referenciado pelo autor e que só existe, segundo ele mesmo afirma em $A$ arte do romance, como única denominação poética possível). 
Nascido em Brno, no seio de uma família erudita de classe média, o escritor possui, em sua trajetória pessoal, passagens pelo partido comunista, marcadas por adesão e expulsão, por três vezes, antes do exílio. O motivo das expulsões se deu devido a sua postura crítica quanto ao regime e a tendência individualista em contraste ao coletivo do movimento totalitário. Em meio a esses movimentos, Kundera escreveu romances que traziam em sua composição o entrelaçamento entre humor e contestação política, os quais, após algum tempo, passaram a sofrer censura pública. Eles são: A brincadeira (1967), Risíveis Amores (1970), A valsa dos adeuses (1972) e A vida está em outro lugar (1973).

Nesse clima de insatisfação e devido a um convite de trabalho na Universidade de Rennes, o autor parte para a França, em 1975, efetivando o seu exílio em 1980, quando recebe a cidadania francesa. Após esse deslocamento, ele ainda publica O livro do riso e do esquecimento (1979), A insustentável leveza do ser (1984) - seu livro mais conhecido - e A imortalidade (1990), seus últimos romances com a versão original em tcheco. A partir de 1995, com a obra A lentidão (1995), Kundera passa a escrever seus romances diretamente em francês ${ }^{6}$, a saber: A identidade (1997), A ignorância (2000) e A festa da insignificância $(2014)^{7}$.

Feitas tais considerações acerca da trajetória bibliográfica percorrida ao longo da vida do autor, é mister realizar uma divisão da literatura de Kundera em dois ciclos: o tcheco (textos escritos pelo autor em tcheco) e o francês (textos escritos diretamente em francês). Tal separação, inspirada pela mudança da língua da escrita, nos permite levantar a hipótese que o exílio experienciado em sua história pessoal e também vivenciado na sua escrita ganha, com a escolha do francês para a redação de seus romances, uma (in)visibilidade expressamente marcada. Isso porque, depois de vinte anos de exílio, é justamente o abandono da língua materna como língua criativa a evidenciar as cicatrizes das perdas que o estado de exílio comporta.

A partir dessa nova condição, Kundera automaticamente se torna um imigrante, um estrangeiro, o que lhe oferece a oportunidade de "habitar dois mundos" (RICHARD, p.127, $2015)^{8}$, experiência que lhe permite uma perspectiva privilegiada de aproximação entre dois olhares diferentes sobre a existência. Nesse sentido, é coerente também pensar que essa posição amplia suas reflexões sobre a Europa Oriental vista pela Europa Ocidental e da Europa Ocidental vista pela Europa Oriental. Todos aspectos, esses, positivos para um intelectual, longe das acepções geralmente utilizadas em chave negativa de termos como 'estrangeiro' e 'desterrado', os quais são muito explorados na literatura sobre exílio, em que o apelo emocional ao deslocamento do ser em relação ao mundo é priorizado. Há, dentro dessa concepção, uma voz que conduz à origem e ao sentimento de nação já bastante explorado

6 Quanto a sua produção ensaística, desde o primeiro livro de ensaios, A arte do romance (1988), o autor escreve originalmente em francês e isso se estende aos outros três livros posteriores: Os testamentos traídos (1993), A cortina (2005), Um encontro (2009).

7 Além de se aventurar em romances e ensaios, Kundera possui também, em sua trajetória literária, algumas publicações de poemas e uma peça teatral inspirada em Diderot.

8 Nesse artigo, a teórica traz o trecho de uma entrevista realizada por Phillip Roth com Kundera, onde é mostrada a visão da imigração como ganho e oportunidade. 
literariamente durante o século XIX.

Por consequência, o exílio coloca em questionamento as reflexões relativas aos sentimentos de pertencimento e não pertencimento vinculados à noção de pátria e terra, de forma a construir um pensamento sobre perdas e ganhos que podem ser obtidos a partir dessa experiência. Kundera, então, aproxima-se bastante das visões de Todorov, na sua autobiografia $O$ homem desenraizado:

O homem desenraizado, arrancado de seu meio, de seu país, sofre em um primeiro momento: é muito mais agradável viver entre os seus. No entanto, ele pode tirar proveito de sua experiência. Aprende a não mais confundir o real com o ideal, nem a cultura com a natureza: não é porque os indivíduos se conduzem de forma diferente que deixam de ser humanos. Às vezes ele fecha-se em um ressentimento, nascido do desprezo ou da hostilidade dos anfitriões. Mas, se consegue superá-lo, descobre a curiosidade e aprende a tolerância. Sua presença entre os "autóctones" exerce por sua vez um efeito desenraizador [...]. (TODOROV, 1999, p.27)

e de Edward Said, em Reflexões sobre o exílio, textos que tratam sobre a experiência dessa condição:

Embora talvez pareça estranho falar dos prazeres do exílio, há certas coisas positivas para se dizer sobre algumas de suas condições. Ver "o mundo inteiro como uma terra estrangeira" possibilita a originalidade da visão. A maioria das pessoas tem consciência de uma cultura, um cenário, um país; os exilados têm consciência de pelo menos dois desses aspectos, e essa pluralidade de visão dá origem a uma consciência de dimensões simultâneas, uma consciência que para tomar emprestada uma palavra da música —é contrapontística. (SAID, 2003, p.58)

Tais excertos colocam em evidência o fato de que a condição do exílio, por se tratar de uma experiência humana, é mais ampla e múltipla do que única e limitada ao sofrimento, bastante estigmatizado e explorado. Longe de desconsiderar essa particular percepção de expatriação, o que se pretende é ressaltar que as condições antes, durante e, até mesmo, após essa migração são um caminho de diversas rotas e que não é possível compreender isso a partir de uma única experiência.

Ainda assim, mesmo levando em conta tais entendimentos, no que diz respeito a Kundera, devido ao processo que orientou a sua saída da República Tcheca, parece haver uma maior preocupação, por parte dele, com o que é escrito e como isso será colocado de forma pública, sendo um dos reflexos das censuras que lhe foram impostas e que tiveram como consequência a sua reclusão como escritor e o afastamento do público, negando-se a muitas entrevistas, restringindo e controlando tudo o que é publicado utilizando o nome dele. Uma das causas desse comportamento parece ter sido a livre interpretação que um jornalista fez de uma entrevista que Kundera lhe concedeu, relatada com fervor em seu livro de ensaios 
A arte do romance .

Maldito seja o escritor que permitiu pela primeira vez que um jornalista reproduzisse livremente suas opiniões! Ele começou o processo que não poderá senão levar o escritor ao desaparecimento: aquele que é responsável por cada uma de suas palavras. [...] A entrevista aparece. Você se consola: será esquecida depressa! Absolutamente: ela será citada! Mesmo os universitários mais escrupulosos não distinguem mais as palavras que um escritor escreveu e assinou e suas opiniões reproduzidas. Em 1985, decidi firmemente: entrevistas nunca mais. Apenas diálogos, co-redigidos por mim, acompanhados de meu copyright, qualquer outra opinião atribuída a mim deve ser considerada, a partir daquela data, como falsa. (KUNDERA,1988, p.113-114)

Talvez seja por esse receio com a utilização equivocada das suas palavras que, em muitos dos romances escritos já fora de seu país, esteja presente todo um cuidado ao se referir ao exílio, na tentativa de evitar que a sua própria história individual seja mais levada em conta do que os questionamentos sobre a existência presentes na sua obra, algo que encontra muita força quando Kundera afirma, ainda em $A$ arte do romance, que a compreensão de seus romances não exige conhecimento de nada além do que a escrita traz e que o romancista "não é nem historiador nem profeta: ele é explorador da existência" (1988, p.43). Destarte, ressalta-se a necessidade de uma abordagem da exploração do tema do exílio nos estudos sobre o autor, de forma que haja a atenção simultânea para as condições impostas pelo teor político e pela própria experiência na construção literária do texto.

Dentre todas as possíveis referências a essa experiência, uma delas merece nota devido ao fato de oferecer uma parte de uma reflexão em torno do exílio, no que tange aos escritores e às suas vinculações com as palavras, e se encontra dentro de outro de seus livros de ensaios, intitulado Um encontro. O autor, inspirado pelo discurso "Por uma ontologia do exílio" de Vera Linhartova - poeta, compatriota e exilada residente na França -, faz considerações sobre essa dupla relação entre língua e nacionalidade, de modo que a existência de escritores em exílio escrevendo em outra língua não é só possível, como também caracteriza um exercício de coragem e algo comumente realizado por uma série de outros escritores.

Quando Linhartova escreve em francês, continua a ser uma escritora checa? Não. Passa a ser uma escritora francesa? Também não. Está alhures. Alhures como

9 Em relação a seus romances, isso pode ser percebido também no que se refere a seu cuidado com as traduções. Sobre isso, Kundera afirma: "O choque causado pelas traduções de A brincadeira, me marcou para sempre. Felizmente, mais tarde, encontrei tradutores fiéis. Mas também, infelizmente, menos fiéis... Contudo, para mim que praticamente não tenho mais o público tcheco, as traduções representam tudo. É por isso que, há alguns anos, me decidi enfim a pôr ordem nas edições estrangeiras dos meus livros. Tal coisa não se fez sem conflitos nem sem fadiga: a leitura, o controle, a revisão de meus romances, antigos e novos, nas três ou quatro línguas que sei ler ocuparam inteiramente todo um período de minha vida...

O autor que se empenha em cuidar das traduções de seus romances corre atrás das inúmeras palavras como um pastor atrás de um rebanho de carneiros selvagens; triste figura para si mesmo, risível para os outros.” (KUNDERA, 1988, p.109-110) 
outrora Chopin alhures como mais tarde, cada à sua maneira, Nabokov, Beckett, Stravinsky, Gombrowicz. [...] Seja como for, depois do seu texto radical e luminoso já não se pode falar do exílio como se falou até agora. (KUNDERA apud GONÇALVES, 2012, p. 128)

A própria poeta, em suas ponderações sobre o exílio, afirma a potencialidade desse movimento, evidenciando a fluidez e o caráter transitório e deslocado:

A su vez, el exilio voluntario puede ser abordado de dos maneras diferentes. Puede ser concebido como una huida frente a una adversidad y una amenaza inmediatas; será entonces experimentado como un tiempo suspendido, provisional, en espera del improbable regreso al lugar y al momento previo a la ruptura. $\mathrm{O}$ bien puede verse como un punto de partida hacia otro lugar, ignoto por definición, abierto a todas las posibilidades y en esta óptica será vivido como un tiempo pleno, como un comienzo sin meta definida y, sobre todo, sin la engañosa esperanza de un regreso. Ahora bien, es evidente que, para esta segunda opción, el propio término de "exilio" es particularmente inapropiado. Pues para quien se va sin pesar y sin deseo de volver atrás, el lugar recién abandonado importa mucho menos que el lugar a donde habrá de llegar. En adelante ya no vivirá "fuera de este lugar", sino que se adentrará en el camino que lleva a un "sin lugar", hacia ese otro lugar para siempre fuera de su alcance. Tal como el nómada, estará en "su casa" en donde quiera que ponga el pie. (LINHARTOVA, 2018, p. 8) $)^{10}$

Ainda assim, ao mencionar Vera, Kundera, ao colocar em questionamento a existência humana exilada, em suas narrativas pós exílio, mostra perspectivas diferentes de possibilidades que estão além do senso comum, potencializando a experiência. O exilado e o exílio não possuem uma só forma e refletir acerca dos dois também implica em tentar compreender as relações entre memória, narrativa e identidade, principalmente nos romances do ciclo francês: A lentidão (1995), A identidade (1997) e A ignorância (2000).

\section{CICLO FRANCÊS E AS IMAGENS DE MEMÓRIA}

Conforme afirmado anteriormente, esse ciclo inaugura a escrita de Kundera em língua francesa e apresenta mudanças na estrutura das narrativas, bem como na abordagem dos

10 "Por sua vez, o exílio voluntário pode ser abordado de duas maneiras diferentes. Pode ser percebido como uma fuga frente a uma adversidade e uma ameaça imediatas; será então experimentado como um tempo suspendido, provisório, na espera do improvável regresso ao lugar e ao momento anterior à ruptura. Ou bem pode ser visto como um ponto de partida para outro lugar, desconhecido por definição, aberto a todas as possibilidades e nessa ótica será vivido com um tempo pleno, como um começo sem meta definida e, sobretudo, sem a esperança enganosa de um retorno. Ora, é bem evidente que, para essa segunda opção, o próprio termo 'exílio' é inapropriado. Pois para quem se vai sem pensar e sem desejo de voltar atrás, o lugar recém abandonado importa muito menos do que o lugar aonde haverá de chegar. A partir de agora não viverá mais 'fora deste lugar', mas entrará no caminho que o leva a um 'sem lugar', para esse outro lugar para sempre fora de seu alcance. Assim como o nômade, ele estará em 'sua casa' onde quer que ponha os pés". (tradução nossa) 
temas da memória e de sua representação. Com isso, observa-se que, além de desempenhar a função de retratar o passado, a memória aparece nominalmente nos romances a partir de imagens, as quais se refletem na organização dos capítulos, bem como na construção dos personagens, podendo ser vistas como o fio condutor que comanda o trabalho envolvido na narrativa: duração, espelhamento e repetição são as imagens utilizadas pelo romancista para se referir a esse tema em cada uma das narrativas. 11

No que concerne à imagem de duração, presente no romance A lentidão, Kundera realiza, em sua montagem, um trabalho estrutural por meio do jogo entre rapidez e lentidão presente na representação da memória.

Há um vínculo secreto entre a lentidão e a memória, entre a velocidade e o esquecimento. Imaginemos uma situação das mais comuns: um homem andando na rua. De repente, ele quer se lembrar de alguma coisa, mas a lembrança lhe escapa. Nesse momento, maquinalmente, seus passos ficam mais lentos. Ao contrário, quem está tentando esquecer um incidente penoso que acabou de viver sem querer acelera o passo, como se quisesse rapidamente se afastar daquilo que, no tempo, ainda está muito próximo de si.

Na matemática existencial, essa experiência toma a forma de duas equações elementares: o grau de lentidão é diretamente proporcional à intensidade da memória; o grau de velocidade é diretamente proporcional à intensidade do esquecimento. (KUNDERA, 1995, p. 30-31)

Assim sendo, ao longo do texto, que contrasta passado e presente, pode-se observar que a duração está sendo estabelecida tanto no nível do número de personagens, quanto pelo intercalar dos fragmentos de narrativa de cada um deles. A começar pelo fato de que a trama se desenvolve durante a estadia de um Milan e uma Vera (ambos ficcionais) em um castelo na Normandia - lugar que também será cenário das aventuras dos personagens principais: Chechoripski, Immaculata, o cameraman, Pontevin, Vincent, Berck e Julie; além de também servir de menção ao castelo do romance de Vivant Denon, Point de landemain, no qual se passa a aventura erótica de Madame T. e o cavaleiro.

Todos os personagens possuem na narrativa, além do vínculo espacial, um vínculo temporal, visto que todos os acontecimentos se desenvolvem na duração de uma noite, característica que é responsável por criar e gerenciar movimento na construção da narrativa12 e evidenciar a velocidade trazida pela imagem da memória. E isso pode ser percebido seja nas ações dos personagens, seja no romance como um todo. Por consequência, intitular o romance de A lentidão serve como uma ironia bem aplicada pelo autor, uma vez que o desenvolvimento rápido da narrativa se contrapõe ao título e ressalta a crítica à modernidade

11 Sobre isso, ver dissertação de Lorena do Rosário Silva, intitulada "Imagens da memória e seus efeitos em A lentidão, A identidade e A ignorância, de Milan Kundera”, UFMG, 2018.

12 Por se tratar de um romance que explora a duração do tempo, junto da percepção dele como acelerado, Kundera opta por demonstrar, na narrativa os diversos acontecimentos simultâneos e algumas vezes relacionados na esfera da narração. Essa junção atribui um aceleramento à narrativa, de maneira a criar um movimento. 
e sua velocidade, temas presentes em seu conteúdo.

Semelhante percepção do emprego da imagem de memória é encontrada em $A$ identidade, narrativa que apresenta a memória a partir da alteridade. A ação desenvolvida parte da aventura de um casal que, em uma viagem de fim de semana, começa a se estranhar e tal sentimento se instala entre eles a tal ponto que os faz questionar acerca da relação e de si mesmos. Logo, ainda que não seja diretamente mencionada com tanta ênfase quanto em A lentidão, a memória surge por meio do efeito de espelhamento. De fato, Chantal é apresentada por meio de seu passado e Jean-Marc, enquanto o contrário também é verificado: Jean-Marc é colocado em relação a seu passado e Chantal. Tal contraposição é a responsável por provocar esse efeito de espelho, o que é atestado também na estrutura do romance, em que os capítulos se dispõem proporcionalmente intercalando entre as partes dedicadas a cada um dos personagens, separadamente, e aquelas sobre o casal como um todo.

Além disso, é necessário pontuar que a memória é trazida para ressaltar a tensão entre passado e presente, pois a construção de uma identidade pela outra só se dá em vista do que houve e isso se contrapõe ao relacionamento de ambos os personagens.

Subiu para o quarto, tentou penosamente adormecer e despertou no meio da noite depois de um longo sonho. Nele apareciam exclusivamente pessoas de seu passado: a mãe (morta havia muito tempo) e sobretudo o ex-marido (fazia anos que não o via e o homem do sonho não se parecia com ele, como se o diretor do sonho tivesse escolhido o ator errado para o papel); estava lá com a irmã, dominadora e enérgica, e a nova esposa (ela jamais a vira; no entanto, no sonho, não duvidava de sua identidade); no fim, ele lhe fazia vagas propostas eróticas, e sua nova esposa beijou Chantal fortemente na boca, tentando introduzir a língua entre seus lábios. Línguas se lambendo sempre lhe repugnavam. Na verdade, foi esse beijo que a despertou.

O mal estar suscitado pelo sonho era tão grande que ela se esforçou para decifrar a razão. O que a perturbou tanto, pensou, foi a supressão do tempo presente efetuada pelo sonho. Pois ela se agarra apaixonadamente ao seu presente, que não trocaria nem pelo passado nem pelo futuro, por nada no mundo. É por isso que ela não gosta dos sonhos: eles impõem uma igualdade inaceitável das diferentes épocas de uma mesma vida, uma contemporaneidade niveladora de tudo aquilo que o sujeito jamais viveu; desconsideram o presente, negando-lhe sua posição privilegiada. (KUNDERA, 1997, p. 9)

A memória, no sonho, tem a capacidade de enganar totalmente a percepção do tempo, causando um nivelamento de diferentes períodos da mesma vida, e a personagem reflete sobre o quanto isso seja injusto, sendo que o presente deveria ter o privilégio da memória. Uma fina ironia do narrador se afirma neste trecho, em um entrelaçamento entre sonho e realidade, passado e presente, consciente e inconsciente.

Dando prosseguimento à perspectiva das imagens da memória, a última a ser apresentada é a de repetição, desenvolvida no romance $A$ ignorância, e que surge de forma material 
por meio das menções à memória dos personagens principais: Irena e Josef, dois exilados que experimentam o retorno a seu país após vinte anos afastados. Ao longo do texto, são realizadas inúmeras referências ao termo; e não somente isso, a memória também aparece por meio dos seus dispositivos de permanência - objetos como pintura e diários. Em todas elas, há um teor de repetição e construção no que diz respeito ao entendimento dos personagens e da estruturação da narrativa.

Por se tratar de uma narrativa de retorno, é esperado que os personagens vivam a tensão da contraposição do passado e do futuro, produto de um deslocamento que foi político de preservação da própria vida, pois ambos os personagens indireta (Irena) ou diretamente (Josef) foram exilados devido à discordância política quanto ao novo regime. A saída lhes amputou o afeto e a consideração de suas famílias ${ }^{13}$; enquanto a volta lhes amputa a própria liberdade e entendimento de si, pois passam automaticamente a se sentir limitados pelas memórias de seus antigos amigos e parentes.

O vínculo, porém, se desvela roto e no rasgo se instaura uma sensação de estranhamento que se torna uma fenda intransponível quando as tentativas de Josef para despertar interesse em sua nova vida no exterior e suas memórias criadas se mostram totalmente vãs. Irena, portanto, mesmo estando vivendo no mesmo tempo e espaço que sua mãe e amigas, não consegue reestabelecer seus vínculos de forma plena; tampouco Josef, que prefere retornar à Dinamarca e lidar com as memórias de sua esposa morta do que permanecer em Praga e tentar se adequar às suas memórias de antes do exílio.

A partir dessas considerações, as memórias seriam o fio capaz de vincular ou desvincular os afetos. Kundera atenta para o caráter de seleção da memória, tendo em vista a duração da vida humana: há uma limitação em torno do compreender o passado em sua totalidade, o que faz com que a memória retida seja a parte de um todo, em contraposição ao absoluto da vida e de suas experiências.

A memória, ela também não pode ser compreendida sem uma abordagem matemática. O dado fundamental é a relação numérica entre o tempo da vida vivida e o tempo de vida armazenado na memória. Nunca se tentou calcular essa relação e aliás não existe nenhum meio técnico de fazer isso; no entanto, sem grande risco de engano, posso supor que a memória não guarda senão um milionésimo ou um bilionésimo, em suma, uma parcela ínfima da vida vivida. Isso também faz parte da essência do homem. Se alguém pudesse reter na memória tudo o que viveu, se pudesse a qualquer momento evocar qualquer fragmento do passado que quisesse, não teria nada a ver com os humanos: nem seus amores, nem suas amizades, nem suas raivas, nem sua faculdade de perdoar ou de se vingar se pareceriam com os nossos.

[...] a crítica da memória humana como tal. Do que essa pobre coitada é capaz? Ela só pode reter uma pequena parcela do passado, sem que ninguém saiba por

13 Há referências ao fato de que o afastamento trouxe dificuldades na manutenção do contato, como a comunicação precária de Irena com a mãe, a qual fora visitá-la na França após muitos anos em exílio; além da dificuldade e do medo dos parentes de Josef em escrever cartas que seriam confiscadas ou até mesmo realizar ligações por telefone. 
que justamente aquela e não outra, pois essa escolha, cada um de nós a faz misteriosamente, sem controle de nossa vontade e de nossos interesses. (KUNDERA, 2000, p.80-81)

Ainda pensando no trecho acima, cabe ressaltar que o autor afirma, inclusive, o caráter de seleção das memórias como algo sem um critério pré-definido, sem uma lógica aparente que a determina e ambos os personagens observam o retorno a partir disso. Nesse sentido, as várias remissões ao termo terminam por originar a percepção de uma cena de passados sucessivos, quais camadas que se adicionam no entendimento dos personagens e das ações desempenhadas por eles. Destarte, a adição contínua de tais passados, que insistem em voltar, pode ser vista através da imagem de repetição, completando, assim, o conjunto das imagens de memória trazidas nos três romances do ciclo francês analisado.

Para além do fato de evidenciar os romances quanto a esse tema, é necessário estabelecer a compreensão do vínculo estreito e da relação entre narrativa e identidade, no que tange à construção do ser no mundo em experiência. O próprio modo de entendimento de si dentro de uma identidade pressupõe a assimilação de que há uma narrativa sendo colocada em ação, através de um relato.

Conforme Arfuch (2010, p.112),

[...]falar do relato, então, dessa perspectiva, não remete apenas a uma disposição de acontecimentos - históricos ou ficcionais - numa ordem sequencial, a uma exercitação mimética daquilo que constituiria primariamente o registro da ação humana, com suas lógicas, personagens, tensões e alternativas, mas à forma por excelência de estruturação da vida e, consequentemente, da identidade, à hipótese de que existe, entre a atividade de contar uma história e o caráter temporal da experiência humana, uma correlação que não é puramente acidental, mas que apresenta uma forma de necessidade "transcultural".

Com isso, a necessidade de tanto Irena quanto Josef quererem contar, àqueles que habitavam o seu passado antes do exílio, sobre os anos de exílio é a necessidade de construção de um discurso autobiográfico, uma narrativa identitária que é feita, sobretudo, pela relação com o outro. A impossibilidade do relato é a impossibilidade da estruturação de uma identidade, de modo que o não contar implica para eles em um não ser, o principal motivo da angústia e da indignação. Portanto, pode-se refletir que o relato possibilita aos personagens a significação de suas vidas, transformando as memórias na sua história pessoal e, a partir disso, criando a sua identidade.

Além disso, a vida passa a adquirir contornos através da percepção do vínculo entre escrita e sujeito (vide os diários de Josef), e a identidade passa a ser vista, nesse caso, como uma prática da narração de si. O falar de si, a partir das memórias, no discurso narrativo de Irena e Josef ao retornarem à terra natal, seria capaz de unir todos os laços de restos do passado e mostrar, tanto para os outros quanto para eles mesmos, quem eles são ou quem eles se tornaram.

Sendo assim, partindo das narrativas, pode-se estabelecer um elo entre tais imagens 
(duração, espelhamento e repetição) e a figuração do exílio no ciclo francês, evidenciando o quanto o exílio pode ser visto nos romances em que ele não é mencionado e também o quanto a organização das narrativas é reflexo desse deslocamento, que se configura em um constante movimentar.

\section{FIGURAÇÕES DO EXÍLIO}

A experiência do exílio, caso vista da perspectiva de um trauma, possibilita ao exilado a consciência de si como ser em constante transformação e despertencimento. Para alguns escritores, tal experiência será, por muitas vezes, dolorosa a ponto de adquirirem um bloqueio na criação literária; enquanto que para outros será justamente um motivo ou uma potencialização no que se refere à composição de seus textos. Por essa razão, não seria surpreendente a tentativa de associação do exílio, bem como de questões em torno da política e da resistência, aos romances de Kundera, pois, principalmente em A ignorância, ele será trazido como tema central de suas reflexões.

No entanto, nos romances mencionados do ciclo francês, é possível inferir, a partir das imagens, certo tipo de presença desse exílio ${ }^{14}$. A esse tipo de presença, origina-se o entendimento da figuração, justamente por corresponder à visualidade e à apresentação de uma imagem mental. As relações entre escrita e imagem não se constituem como algo novo no campo da literatura: suas remissões mais antigas se relacionam à retórica ${ }^{15}$ e à apreensão de ideias a partir do desenvolvimento de figuras - um exemplo se dá na própria gramática quando se apropria dessa conexão no seu conceito de figuras de linguagem.

Portanto, a referência das imagens como figuração do exílio se valida a partir do momento em que duração, espelhamento e repetição desempenham a percepção de um movimento. Sendo a duração proveniente de uma velocidade, o espelhamento advindo de um contraste e a repetição baseada em um retorno, todas essas imagens acarretam um movimento; logo, evidenciam um deslocamento. É justamente esse deslocamento que se aproxima das relações entre identidade e narrativa, experimentadas em exílio.

Para além disso, estabelece-se uma ligação entre memória e ficção na construção da identidade, seja por meio dos conceitos de ipseidade (identidade-ipse, manutenção de si pela recusa da mudança) e mesmidade16 (identidade-idem, conceito de relação entre diferentes critérios de permanência) de Ricoeur, presentes em O si mesmo como um outro (2014), seja por meio da explicação do que vem a ser a identidade narrativa, em Tempo e Narrativa tomo III: "a história narrada diz o quem da ação. A identidade do quem é apenas, portanto,

14 Sobre as relações entre o escritor Kundera e o exílio, existem alguns trabalhos brasileiros que já começam a tematizar e até mesmo considerar o exílio de Kundera como um eixo epistemológico em sua obra - é o caso do artigo de Verônica Barbosa, intitulado "A questão da identidade em Milan Kundera". Outros trabalhos mais recentes realizados pelo grupo Epistemologia do Romance, da UNB, também expandirão esse diálogo.

15 Principalmente no que diz respeito à criação de um ethos (eu) discursivo por meio de um logos (raciocínio).

16 Tanto os conceitos de ipseidade e mesmidade em parênteses foram retirados do artigo "Mesmidade, ipseidade e vontade: as aporias da noção Ricoeuriana de subjetividade" (2014), de autoria de João B. Botton, pesquisador em Filosofia da UFMG, publicada na revista Impulso. 
uma identidade narrativa." (RICOEUR, 1997, p.424).

Desse modo, através da construção da narrativa de si, o sujeito se torna, ao mesmo tempo, autor e leitor de sua vida. Ricoeur ainda completa:

A noção de identidade narrativa mostra ainda a sua fecundidade no fato de que ela se aplica tanto à comunidade quanto ao indivíduo. Podemos falar de ipseidade de uma comunidade, como acabamos de falar da de um sujeito individual: indivíduo e comunidade constituem-se em sua identidade ao receberem tais narrativas, que se tornaram para um e outro sua história efetiva. (RICOEUR, 1997, p.425)

Mesmo que os romances não sejam equivalentes à compreensão do sujeito Milan Kundera, eles são indícios de um ser que reflete acerca da existência e que se utiliza dela e da História, nem sempre a oficial representada por ele com $\mathrm{H}$ em maiúsculo, para colocar em ações questionamentos e conceitos. Proposição que adquire validação através do autor que, em $A$ arte do romance, afirma:

O romancista desfaz a casa de sua própria vida para, com as pedras, construir a casa de seu romance. Os biógrafos de um romancista desfazem portanto o que o romancista fez, refazem o que ele desfez. O trabalho deles não pode esclarecer nem o valor nem o sentido de um romance, apenas identificar alguns tijolos. (KUNDERA, 1988, p.130)

O ciclo francês representaria, além do desafio de escrever em uma segunda língua, uma oportunidade de reflexão, ainda que indireta, da realidade vivenciada longe da República Tcheca, demonstrando a distância não somente espacial, como também temporal. Uma suspensão propiciada pelo deslocamento e enfrentamento de uma nova realidade.

Ademais, a figuração ressalta o fato de que é possível trazer ao texto o exílio, sem sequer mencioná-lo de forma objetiva. O estranhamento, a confusão, o desencaixe são pontos em comum nas narrativas do ciclo francês; e, embora tais pontos não sejam uma novidade quanto à percepção do contemporâneo, eles, somados à experiência exilada, se potencializam e podem assumir diversas formas - uma diversidade que pode ser percebida na construção da identidade.

Tendo em vista as reflexões realizadas ao longo deste artigo, estabelecer a figuração do exílio no ciclo francês é possível a partir da ótica do deslocamento, esse movimento que é produto da associação e relação entre as imagens de memória de duração, espelhamento e repetição. Tal ação de deslocamento é capaz de colocar em movimento não somente a narrativa no que se refere a sua estrutura, mas também as construções dos personagens. Além disso, as tensões entre passado e presente, características desse ciclo, orientam para essa mobilidade que vai de encontro à experiência do ser em trânsito constante, sem pausa - qualidade do contemporâneo - e também advinda da experiência de exílio. 


\section{CONSIDERAÇÕES FINAIS}

A partir das considerações tecidas ao longo desse artigo, apresentamos a forma como o exílio pode ser percebido na escrita das três narrativas kunderianas - A lentidão (1995), A identidade (1997) e A ignorância (2000) - a partir da perspectiva das figurações, que são advindas das imagens que o autor utiliza para referenciar a memória. Os deslocamentos que tais imagens evocam são percebidos como produtos que evidenciam a natureza da experiência do exilado e, por conseguinte, do exílio experimentado por Kundera, haja vista que o autor afirma a colocação de questões em torno de temas da existência humana. Observa-se, então, a dificuldade de um estabelecimento que não ocorre: a escrita não oferece motivos para pausa e o escrever assegura o pertencimento e a continuidade na adaptação. Assim como na vida pessoal, a escrita kunderiana, sobretudo nesses romances, não admite um território fixo, o movimento se tornou sua própria característica e condição. 


\section{REFERÊNCIAS BIBLIOGRÁFICAS:}

ARFUCH, Leonor. O espaço biográfico: dilemas da subjetividade contemporânea. Tradução: Paloma Vidal. Rio de Janeiro: EduERJ, 2010.

BOTTON, João B. Mesmidade, ipseidade e vontade: as aporias da noção ricoeuriana de subjetividade. Revista Impulso. Piracicaba: v. 24, n. 59, p.25-34, 2014.

KUNDERA, Milan. A arte do romance: (ensaio). Tradução de Teresa Bulhões Carvalho da Fonseca e Vera Mourão. Rio de Janeiro: Nova Fronteira, 1988.

A identidade. Tradução Teresa Bulhões Carvalho da Fonseca. São Paulo:

Companhia das Letras, 2009.

. A ignorância. Tradução Teresa Bulhões Carvalho da Fonseca. São Paulo:

Companhia de Bolso, 2015.

. A lentidão. Tradução Maria Luiza Newlands da Silveira, Teresa Bulhões Carvalho da Fonseca. São Paulo: Companhia das Letras, 2011.

LINHARTOVÁ, Vera. Por uma ontologia del exilio. Traducción de Verónica González Laporte. In: Revista de la Universidad de Mexico. México: Exodos, Dossier, p.6-10. Disponível em: https://www. revistadelauniversidad.mx/articles/4db27177-c7c2-47fe-ba3f-8929a4b055dd/por-una-ontologia-delexilio. Acessado em: 30 out 2020.

NORA, Pierre. Entre memória e história: a problemática dos lugares. In: História e Cultura. Revista do programa de estudos pós-graduação em História e do Departamento de História da PUC/SP. Projeto História, n.10. São Paulo: EDUC, p.7-28, 1993.

RICHARD, Rosimara. A essência da problemática existencial moderna na trilogia kunderiana. In: DiaLogos, Rio de Janeiro/RJ, n.9, p. 125-136, 2015.

RICOEUR, Paul. Tempo e narrativa - Tomo III. Tradução Roberto Leal Ferreira; revisão técnica Maria da Penha Villela Petit. São Paulo: Papirus, 1997.

SAID, Edward. Reflexões sobre o exílio e outros ensaios. São Paulo: Companhia das Letras, 2003.

SILVA, Lorena do. Imagens da memória e seus efeitos em A lentidão, A identidade e A ignorância, de Milan Kundera. Dissertação de mestrado. Belo horizonte: UFMG, 2018.

TODOROV. Tzvetan. O homem desenraizado. Tradução de Christina Cabo. - Rio de Janeiro: Record, 1999. 